\title{
Cooperation between university and research institute: best practice from Zilina, Slovakia
}

\author{
Milan Gregor ${ }^{1}$, Jozef Hercko ${ }^{2}$, Miroslav Fusko ${ }^{2}$ and Vladimir Magvasi ${ }^{2}$ \\ ${ }^{1}$ Central European Institute of Technology \\ Univerzitna 6A, 01008 Zilina, Slovakia \\ milan.gregor@ceitgroup.eu \\ ${ }^{2}$ University of Zilina, Faculty of Mechanical Engineering, \\ Univerzitna 1, 01026 Zilina, Slovakia \\ \{jozef.hercko,miroslav.fusko,vladimir.magvasi\}@fstroj.uniza.s
}

\begin{abstract}
This paper present best practice of cooperation between university and research institute realized in Zilina, Slovakia. Creation of common workplace named ZIMS - Zilina Intelligent Manufacturing System offer possibilities to realize common research activities with special focus on industry needs. As the name implies, key focus of workplace is on intelligent manufacturing system. Concept of workplace is based on holonic approach that mean all systems and subsystems are independent. At the end of paper is presented one of result of common research activities, which has been very successful commercialized.
\end{abstract}

Keywords: collaboration, university, research institute, ZIMS.

\section{Introduction}

Mass customization is relatively new paradigm which principle is based in offering of many extending variants of existing product manufactured with costs of mass production. Such production of goods of the same type is different as by classical mass production. It presents production of high amount of product variants of the same product family by competitive costs of mass production and economy of amount. Following that companies must constantly react to changing requirements of customers through innovations of processes to be able to fulfil the expectations of customers in time and with appropriate quality. Factories are pushed to increase the amount of new technologies which nowadays exist as separate elements but without any cooperation within them. Therefore it's necessary for companies to cooperate with research institutions and universities on joint researches and innovation projects. In present, cooperation as such represents for a company an important tool for increasing its competitiveness. [12] Based on this, industry, universities and research organizations need to cooperate. It is necessary not to forget the existence of common partnerships and mutual cooperation within supplier and customer relationships. The 
quality of such relationships is a prerequisite of the future success of a business on a market. [11]

\section{Cooperation to reach Factories of the Future challenges and opportunities}

In 2008 the European Commission created the European Recovery Plan which goal is to support economy of European Union after lingering economic crisis. One of taken action was establishment of Initiatives to support Factories of the Future development. The goal of this initiation is to support the growth of technologies in industry, so the industry will be competitive in global markets. Next after creation of Initiative, EFFRA - European Factories of the Future Research Association was established. Main goal of this association is to determine direction in research and development focused on factories of the future. Publication Factories of the Future Multi-annual roadmap for the contractual PPP under Horizon 2020 published by EFFRA defined researched and development priorities (Fig. 1 shows an example). [1]

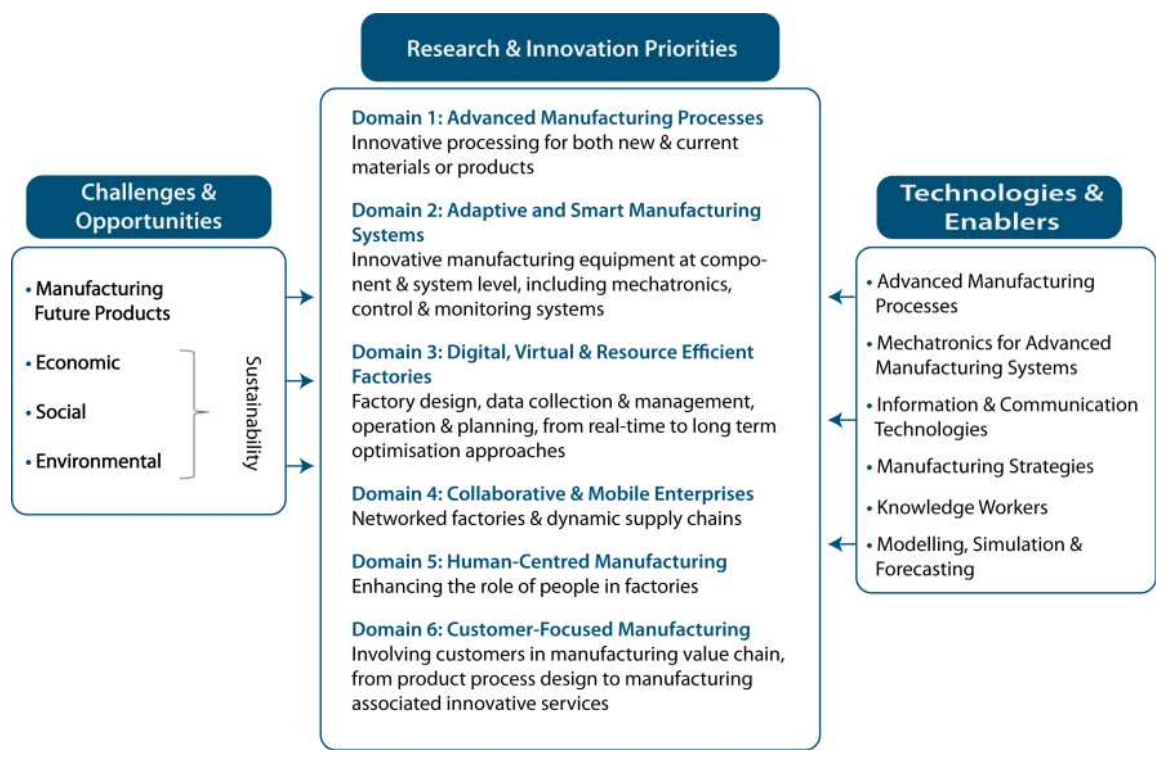

Fig. 1. Research and Innovation Priorities defined by EFFRA. [1]

To reach applicable and competitiveness increasing results cooperation between all interested parties - universities, research institutes and industrial companies is necessary. Only this combination is supposition to realize research and development with potential to implement the results into industry. 


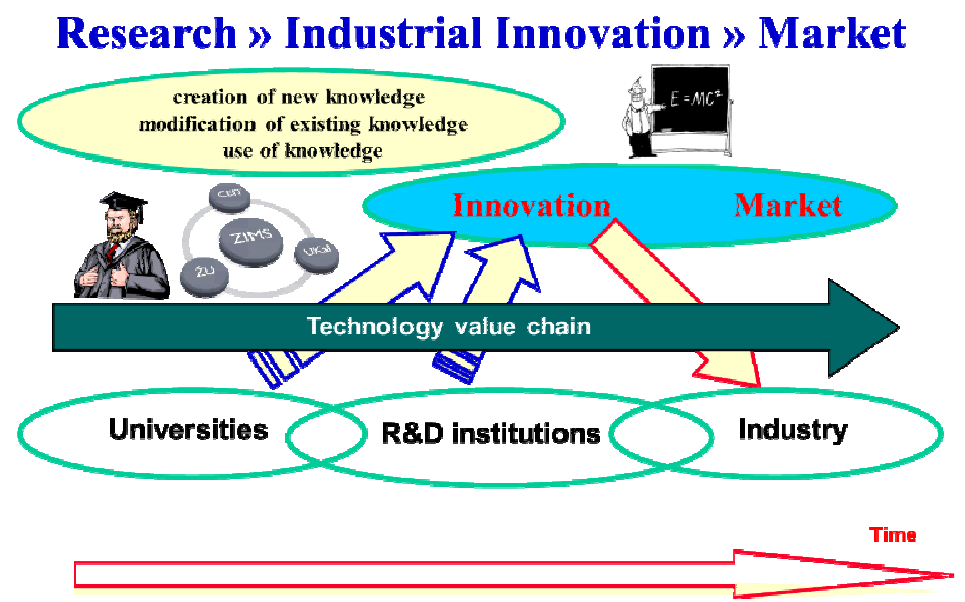

Fig. 2. Model of cooperation between universities, research institutes and industry

On Figure 2 is illustrated connection between industry, research institutes and universities. Research institutes execute the role of "bridge" between industry with specific and realistic research tasks in one hand and universities producing new knowledge in other hand. Connection of research institutes and universities produce new knowledge or modify existing knowledge what produce new innovation for market.

University of Zilina systematically coordinate research activities with special focus on needs of European industry. Since 2000 the University of Zilina invested big amount of money into research focused on digitalization, reverse engineering, rapid prototyping and digital factory. One of new development line of research is Intelligent Manufacturing System (IMS). New intelligent manufacturing systems will require new skills by workers. Based on this University of Zilina focuses on innovative education of students with use of new education technologies and approaches.

\section{Zilina Intelligent Manufacturing System}

Coordination of research and development activities is very important factor. Based on that Central European Institute of Technology and University of Zilina established common workplace named Zilina Intelligent Manufacturing System (ZIMS). ZIMS is established as open platform to cooperate with other interested organization. ZIMS was established in 2009 and in present it is represented with same-named laboratory. Laboratory covers area of more than $1000 \mathrm{~m} 2$ with disposition illustrated on Figure 3. 


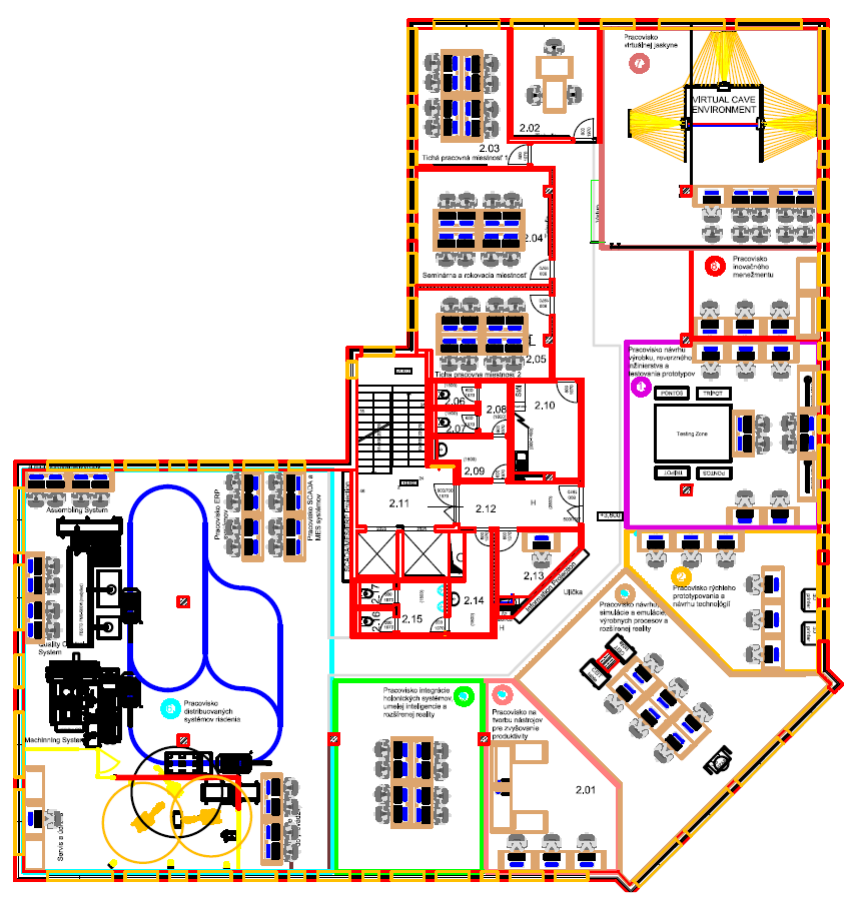

Fig. 3. Disposition of ZIMS.

ZIMS is open collaborative environment supporting creativity, inventions of new solutions and their practical implementation in form of new innovative solutions. This environment fully supports experiments with new, unknown and non-traditional approaches to solve industry-driven tasks. ZIMS has incubation role for potentially new technological and IT related start-ups.

ZIMS laboratory is divided to 3 basic sections (Fig. 4 shows an example) and other supporting sections based on product life cycle of product:

- Section of design, prototyping and testing of product and technology. This section is based on immersive and reverse engineering technologies. Result of work in this section are related with product innovation.

- Section of design of manufacturing and logistic processes. This section is based on use of methods and tools for implementation lean principles to manufacturing and logistic processes. Result of work in this section are related with process innovation.

- Section of production presented with implementation of innovation into manufacturing, this section is characteristic as intelligent manufacturing systems. 


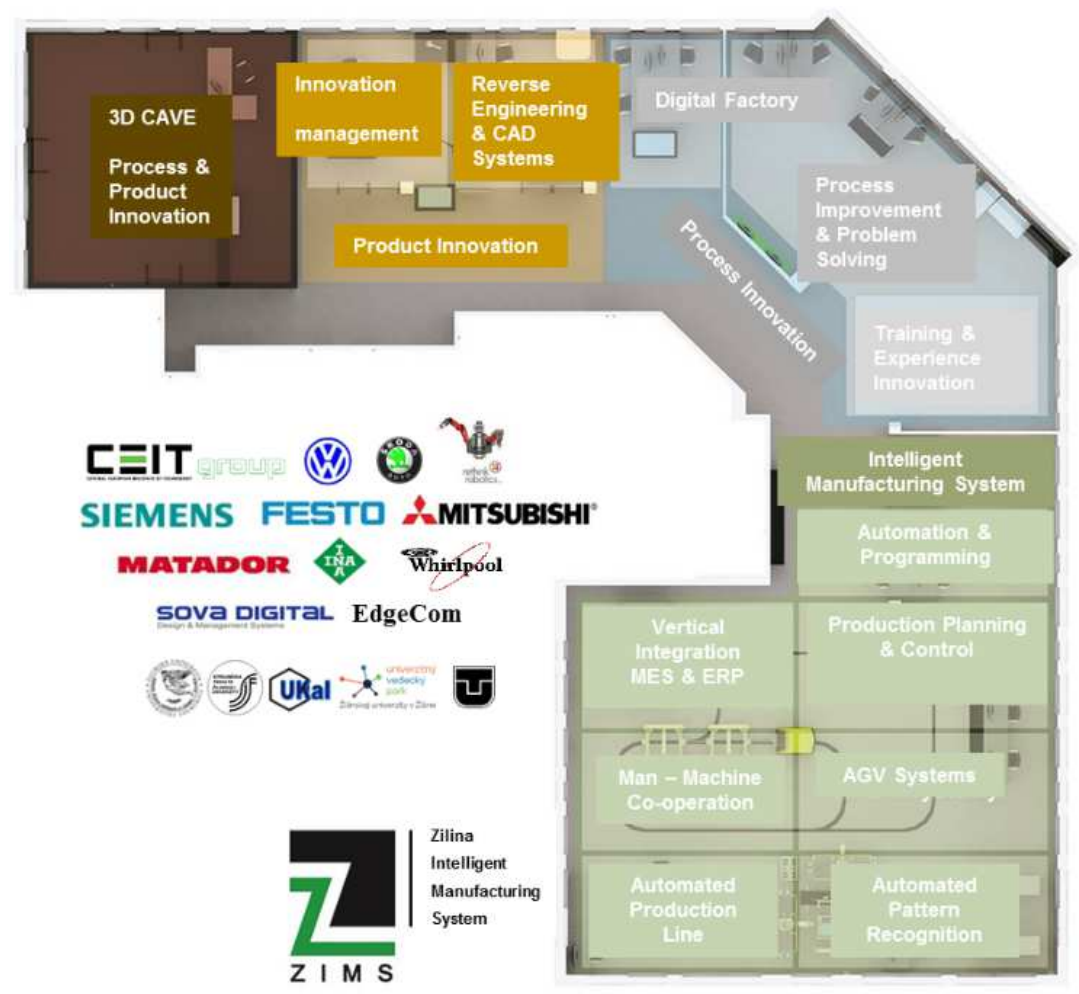

Fig. 4. Sections of ZIMS. [2]

Vision of ZIMS is to create integrated collaborative environment which is connecting three worlds - real, digital and virtual. In this environment has the key role creation, management and use of new knowledge. Target of researchers is to create a unique knowledge management system with includes automated management of knowledge. Connection of data from all three worlds create new cyber-physical system (CPS) illustrated on Figure 5. 


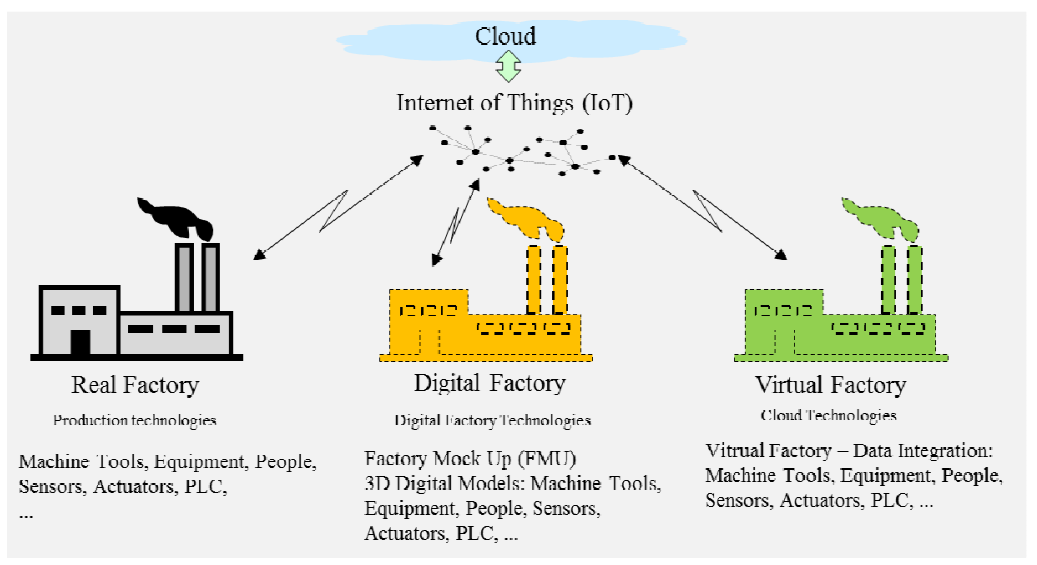

Fig. 5. Concept of CPS building at ZIMS. [2]

All this three worlds has "own factories" which are independent. Integration of this three factories with use of new technologies as Internet of Things and Cloud offers high potential. Smart factories represent data from real world as agile systems with rapid potential to react on customer request. This factories realize rapid changes with use of intelligent features, automation, robotics, automated control, simulation and emulation technologies. One of key technologies used in this world is intelligent manufacturing system. Virtual Factories use virtualization technologies and integration of data from real factories. As input they use data from sensors, action parts, audio-visual information, biometrical data. This factory makes virtual picture of a real factory. Digital factory use digital and digitalization technologies for integration of all part of life cycle management. Digitalization, 3D models, simulation and emulation are used for understanding of complex manufacturing processes. Knowledge mined from such factory can be used for optimization of real manufacturing systems. Concept of collaboration in digital factory is illustrated on Figure 6. 


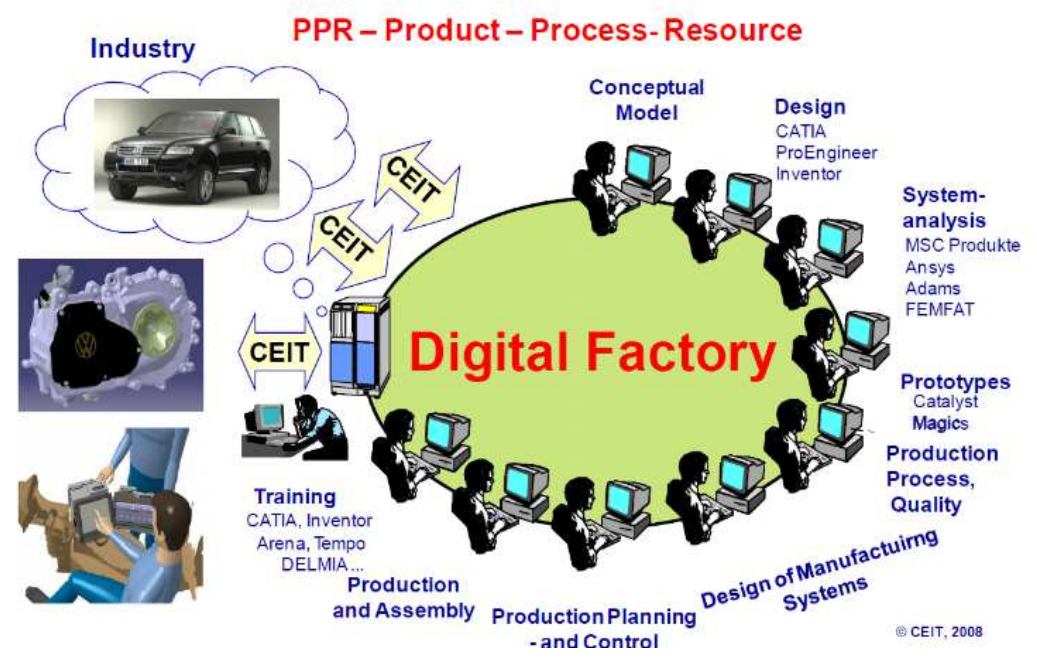

Fig. 6. Digital Factory Concept Built at the University of Zilina [4]

\section{Technology base of ZIMS}

Technology base of ZIMS can be split into three groups of technologies technologies for research and development of product, technologies for research and development of processes and technologies for research and development of manufacturing system.

Technologies for research and development of product are technologies for virtual design, reverse engineering, simulation, virtual testing and validation, virtual prototyping, virtual and augmented reality, immersive technologies, etc.

Technologies for research and development of processes include technologies for virtual design of manufacturing systems, reverse engineering, computer modelling and simulation, ergonomic analysis, virtual and augmented reality, evaluation of performance, financial planning and analysis, etc.

Technologies for research and development of manufacturing system use real manufacturing technologies as adaptive assembly systems, industrial robots, systems for manufacturing planning, intelligent manufacturing systems, etc. 


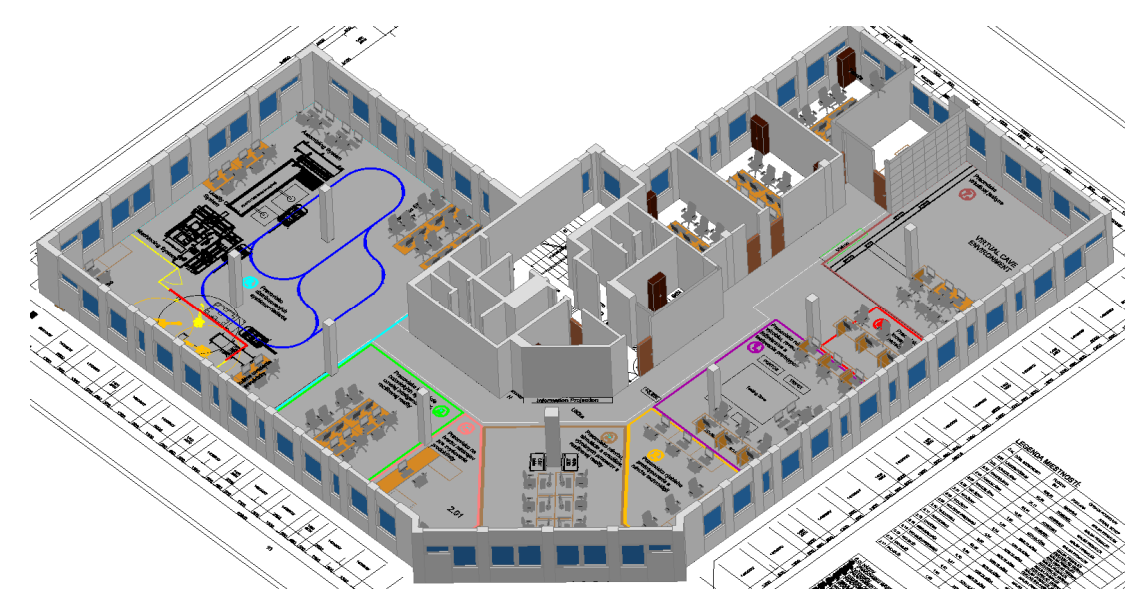

Fig. 7. Layout of ZIMS.

ZIMS use technologies for research and development based on new trends in this areas:

- advanced mechatronic systems,

- $\quad$ artificial intelligence,

- newest information and communication technologies,

- $\quad$ advance manufacturing processes,

- $\quad$ modelling, simulation and prediction,

- manufacturing strategies,

- $\quad$ knowledge engineering.

Concept of ZIMS was designed as a holistic system. Individual holon represent the main subsystems and the advanced corporate systems. Holon represents an individual, a unique part of the system (subsystem), which consists of a set of cooperating elements of the lower level. Practical examples of production holon are autonomous and cooperative subsystems, ensuring complete fulfilment of defined tasks (production, storage, transport, monitoring, logistic, etc.).

\section{Result of cooperation}

Cooperation between Central European Institute of Technology and University of Zilina is represented with many common grant projects and projects for industry. Most of them resulted in products which are commercialized. One of most successful product is Concept of Intelligent Logistic Management.

Concept named CEIT Intelligent Logistic Management is based on needs from industry and is based on artificial intelligence. Main contributors to this concept are several companies based in Slovakia and operate in automotive and electro technical industry. This companies defined their needs and CEIT a.s. with strong cooperation with University of Zilina completed this concept. Artificial intelligence that ensures 
autonomous tasks directionally through agent communication should be integrated into an enterprise system. [6], [7] Principles of this concept is described on Figure 8.

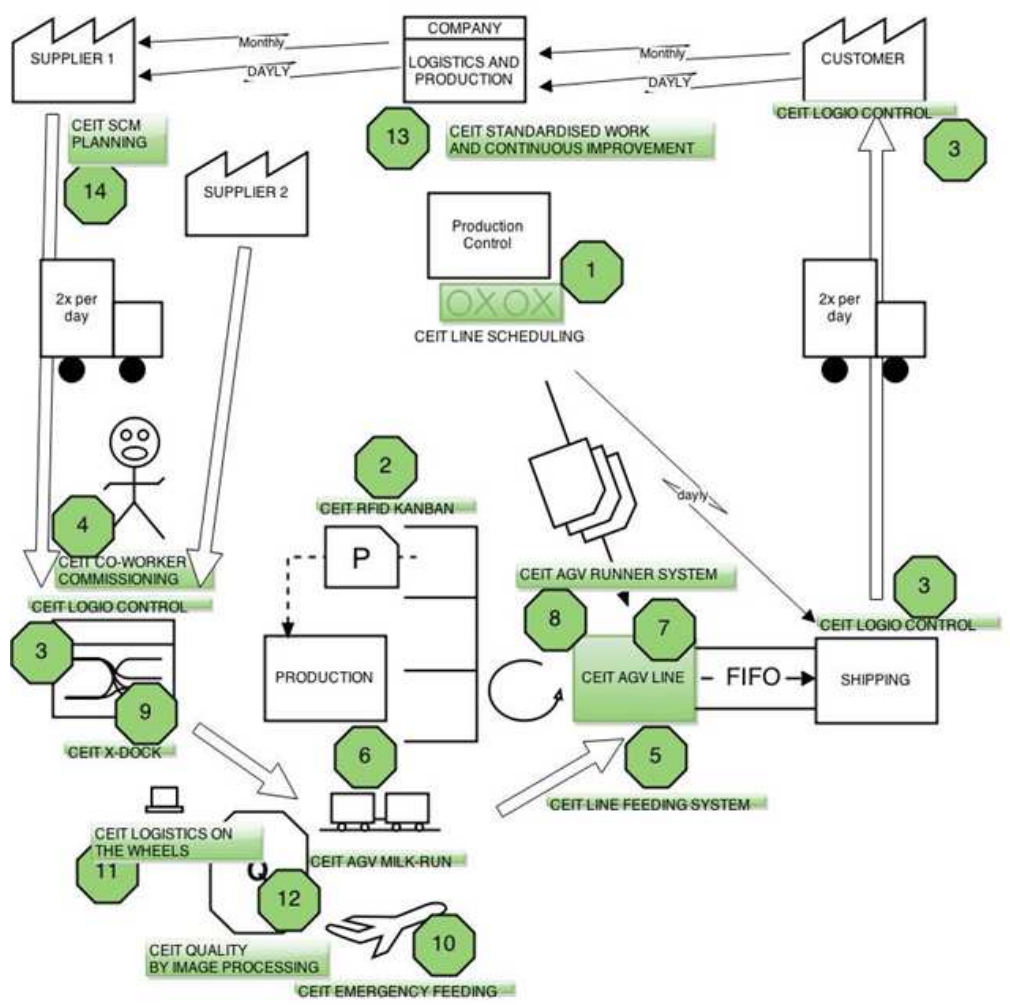

Fig. 8. Concept of CEIT Intelligent Logistic Management. [5]

Concept of CEIT Intelligent Logistic Management is based on 14 solutions, that are together connected and make common "logistics network". At this time, not all of this solution are fully integrated and connected to IT infrastructure of companies. For the future is this concept facing big challenges like Internet of Things [3], Internet of Service and Smart Factory.

Many of this solution has been awarded directly to CEIT, or to companies where has been solution implemented. For example CEIT has been awarded by Ministry of Economy as „Innovative Act of the Year“ for practice game. This game has been used for practice new logistic concept to thousands of employees and suppliers of Volkswagen Slovakia. Next awards achieve Volkswagen Slovakia as ,most lean company“ in Volkswagen Group or „Lean \& Green Efficiency Award“ for they activities in field energy efficiency. The biggest award achieved by Volkswagen Slovakia with strong contribution of CEIT Intelligent Logistic Management is "mach18.FACTORY Oscar", which Volkswagen Slovakia achieved in 2015 as best plant of Volkswagen Group. 
The key solution of CEIT Intelligent Logistic Management is automated guided vehicle $(\mathrm{AGV})$. Currently there are two types used AGV - run under version and towing version (Fig. 9 shows an example). CEIT AGV systems has this advantages / features: [5]

- $\quad$ High speed - up to $2 \mathrm{~m} / \mathrm{s}$

- $\quad$ High towable weight - up to $3000 \mathrm{~kg}$

- $\quad$ Brake energy regeneration

- Wireless monitoring and control system

- $\quad$ Automatic charging

- Safety scanners

- Towing and under-run version

Number of features is during years of development and implementation in industry in Central Europe is growing. Since first generation with few basic features is current generation full of safety and operational features customized and developed based on industrial feedback.

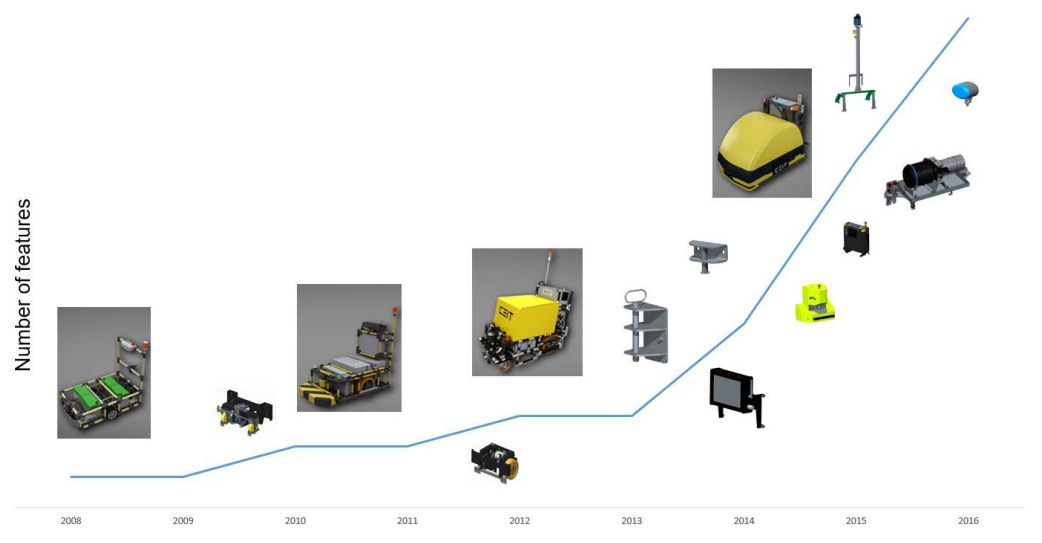

Fig. 9. Features of AGV.

Under-run AGV system can be used as a movable mounting table. AGV broke through device supporting frame, catches him and pulls in any place where he left it. This type of device is used in particular for the transport of parts which are sensitive to handling, respectively during manipulation threaten to damage.

Towing AGV system (Fig. 10 shows an example) is able to take more wagons and that mean take much more material at once. This advantage is able to use with material, which use in production is high. [8] This feature is supported with automatic system of connecting and disconnecting wagons by automatic system. 


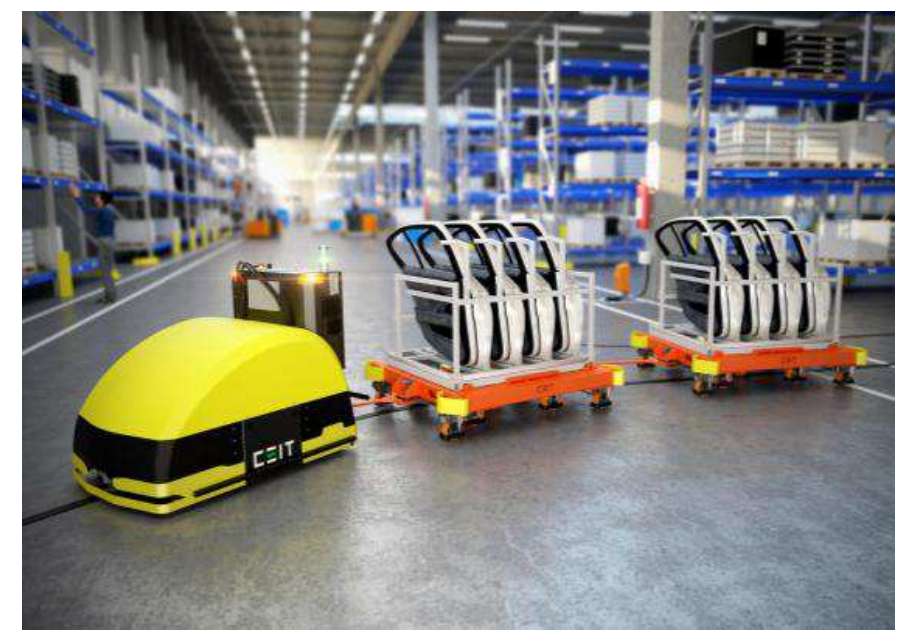

Fig. 10. CEIT AGV systems - towing version

Loading and unloading of pallets from/to AGV system is provided by peripheral devices. In case of big pallets it used "c-frame". Principle of this pallet exchange is in exact stop of AGV in front of frame, mechanical part from wagon take the pallet on board and AGV continue in route (Fig. 11 shows an example). [9]

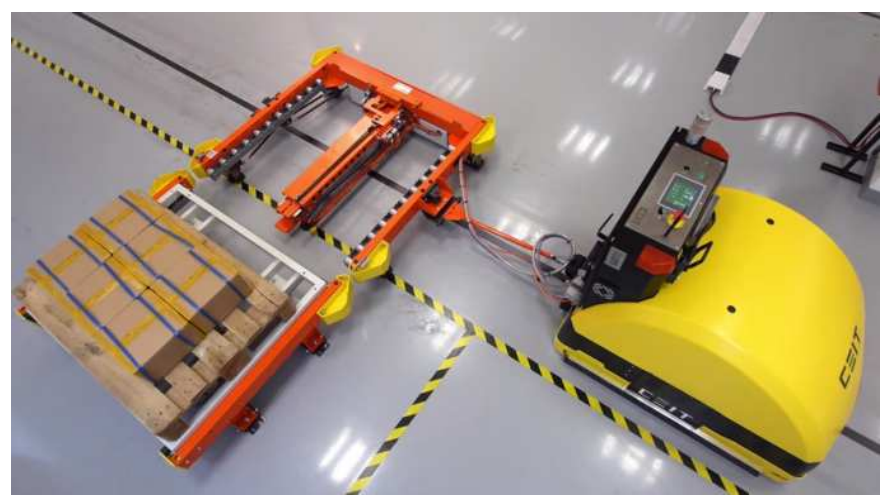

Fig. 11. AGV systems automated pallet loading

One of the main benefits of the AGV is costs reduction by reducing work-in-process, as well as cost savings for employees who are required to operate the truck by manual logistics. [5] 


\section{Conclusion}

Nowadays, active work in the area of cooperative management may help companies not only to keep their position on the market and it can even enhance its competitiveness and find new perspective partners. [10] Cooperation between research institutes and universities should bring high level of innovation for industry. This connection allows to transfer into practice the latest findings from research which has an impact on all stakeholders - universities have opportunities to use the acquired knowledge in the learning process and also in basic research, research institutions are able to transfer the latest knowledge directly to the industry and the industry as end user can significantly increase their competitiveness and those to be successful in the global market.

Acknowledgments. This paper was made about research work support VEGA 1/0936/16.

\section{References}

1. European Commission: Factories of the Future - Multi-annual roadmap for the contractual PPP under Horizon 2020, European Commission, (Brussels (2013).

2. Gregor, M., Hercko, J., Grznar, P.: The factory of the future production system research. In: 21st International Conference on Automation and Computing: Automation, Computing and Manufacturing for New Economic Growth, pp. 254--259. IEEE Press, Glasgow (2015)

3. Gregor, M., Magvasi, V., Gregor, T.: Internet of Things - IoT (in Slovak). ProIN. vol. 16 (2), pp. 35--41 (2015)

4. Gregor, M., Medvecky, S.: Application of Digital Engineering and Simulation in the Design of Products and Production Systems. Management and Production Engineering Review vol. 1 (1), pp. $71--84$ (2010)

5. Micieta, B., Hercko, J., Botka, M., Zrnic, N.: Concept of intelligent logistic for automotive industry. J. of App. Eng. Sci. vol. 14 (2), pp. 233--238 (2016)

6. Micieta, B., Binasova, V., Haluska, M.: The approaches of advanced industrial engineering in next generation manufacturing systems. Communications: scientific letters of the University of Zilina vol. 16 (3A), pp. 101--105 (2014)

7. Micieta, B., Gaso, M. and Krajcovic, M.: Innovation performance of organization. Communications: scientific letters of the University of Zilina vol. 16 (3A), pp. 112--118 (2014)

8. Micieta, B, Zavodska, L., Rakyta, M., Binasova, V. Sustainable Concept for Green Logistics and Energy Efficiency in Manufacturing. In Katalinic, B. (ed.) DAAAM International Scientific Book 2015, pp. 391--400. DAAAM International, Vienna (2015)

9. Mleczko, J., Micieta, B., Dulina, L.: Identification of bottlenecks in the unit make to order production. App comp sci vol. 9 (2), pp. $43--45$ (2013)

10.Soviar, J.: Cluster initiatives in Zilina region (Slovak republic). Economics \& management = Ekonomika ir vadyba, vol. 14, pp. 528--534 (2009)

11.Soviar, J., Zavodska, A.: Knowledge and its creation - the case of introducing product to the Market. Business: Theory and Practice 12 (4), pp. 362--368 (2011)

12.Vodak, J, Soviar, J., Lendel, V., Varmus, M.: Proposal of model for effective management of cooperation activities in Slovak companies. Communications: scientific letters of the University of Zilina vol. 17 (4), pp. 53--59 (2015) 